\title{
The Electricity Security in Nigeria: Design and Analysis of 750-kV Mega Grid
}

\author{
Ademola Abdulkareem¹, Victoria Oguntosin², Oluwatimileyin Dare ${ }^{3}$ and Adesina Lambe Mutalub ${ }^{4}$ \\ ${ }^{1,2,3}$ Electrical \& Information Engineering, Covenant University, Ota, Ogun State, Nigeria. \\ ${ }^{4}$ Electrical and Computer Engineering Department, College of Engineering and Technology, Kwara State University, Malete,
} Nigeria.

\begin{abstract}
Nowadays, due to the ever-increasing global energy demand and the complex option for an individual to install renewable power generation at his/her residence, it has become imperative to operate power plants that deliver energy to transmission and distribution systems at a reduced power loss and at the same time maximize efficiency. Therefore, the need arises to construct cost effective high transmission lines considered at Extra High Voltage (EHV) levels. In this study, the mechanical structures and electrical line parameters of a $750-\mathrm{kV}$ single-circuit 4 conductors per bundle based on existing standards were designed. These EHV levels are then analyzed and the results obtained are compared with the 330$\mathrm{kV}$ lower voltage levels in order to extract the benefits. The implementation of the designed $750-\mathrm{kV}$ grid in Nigeria transmission system results in a significant reduction in the systems' power losses in comparison to the existing $330-\mathrm{kV}$ system.
\end{abstract}

Keywords: Mega grid, Security, transmission line, power loss,

\section{INTRODUCTION}

The importance of an efficient and reliable power generation system cannot be overemphasized. It is the key to better standard of living and economic development in any nation. The power system encompasses the conveying of electric power generated at the power generation stations to the final consumers. This electric power is transmitted to the point of consumption or load centers with the aid of transmission lines. Transmission network lines are very important in getting power to the consumers as most generation plants in a bid to be closer to the needed resources are often sited far from load centers. Transmission system usually deals with very high voltages such as $33-\mathrm{kV}, 66-\mathrm{kV}, 132-\mathrm{kV}, 330-\mathrm{kV}$ and $765-\mathrm{kV}$. At these voltages, powers are transmitted to the distribution systems directly from the generating stations. The Transmission system is a link between generation and distribution systems. The other aspect of the power system that employs power lines is the distribution system that ensures that the transmitted power reaches the end consumers. Distribution involves stepping down very high voltage to lower voltage levels and power is distributed for both domestic and industrial consumption. In the operation of these transmission lines, losses due to resistance of the conductor and other factors are bound to occur and these losses make the power system less efficient. These losses further reduce the already inadequate power thereby crippling the nation's industrial and economic growth.

Since system loss is a considerable cost to utilities, consumers and the host country, its evaluation and reduction have been a unique area of interest to researchers [1]. Over the years, several methods have been developed to reduce these losses to the barest minimum, the most effective so far being extra high voltage transmission. The current practice in developed countries such as United States of America, Canada, Japan, Venezuela, Korea, Brazil, India, and Russia is the construction of infrastructure capable of transmitting electric power at a very high voltage such as $765-\mathrm{kV}$ or above [2].

In Nigeria, there is a huge deficit in terms of the power being generated by the nation. This is as a result of stagnant power generation and an ever-increasing power demand. This everrising demand is as a result of the country's huge population of about 200 million people which has a corresponding average annual growth rate of $2.5 \%$ [3]. The widening gap between demand and supply of power has led to the loss of many small and medium industries which have in turn led to a higher unemployment rate. Unfortunately, this deficit has been allowed to grow over the years due to uncoordinated investments in generation, transmission and distribution sectors and also due to the poor execution of power projects.

The lack of a proper maintenance culture [4], vandalism and the poor state of transmission staff have also been identified as challenges that plagued the transmission sector. In addition to the above challenges, the Nigerian power sector has low efficiency due to a large amount of losses which translate to a huge financial drain $[5,6]$. For a country with such a large population and a meagre peak generation of 5,074.70 MW [7], the transmission losses should be at its barest minimum. At the average generation level, Power consumption per capita is $156 \mathrm{kWh}$ [8] which is extremely low when compared with South Africa's 4,841.28 kWh per capita [9]. Ultra-high voltage transmission lines such as the $765-\mathrm{kV}$ have proven to allow for effective power transmission with minimal losses. 


\begin{tabular}{l|l|l|l|l|l|l|l|l}
\hline \multicolumn{2}{c}{ Table 1. ACSR for EHV transmission lines } \\
\hline \multirow{2}{*}{$\begin{array}{l}\text { Code } \\
\text { Name }\end{array}$} & Al & Steel & $\begin{array}{l}\text { Overall } \\
\text { diameter }\end{array}$ & $\begin{array}{l}\text { Total } \\
\text { Sectional } \\
\text { Area }\end{array}$ & $\begin{array}{l}\text { Approx. } \\
\text { Weight }\end{array}$ & $\begin{array}{l}\text { Nominal } \\
\text { Breaking } \\
\text { load }\end{array}$ & $\begin{array}{l}\text { Resistance } \\
20^{\circ} \mathrm{C}\end{array}$ & $\begin{array}{l}\text { Current } \\
\text { Rating }\end{array}$ \\
\cline { 2 - 10 } & $\mathrm{No} / \mathrm{mm}$ & $\mathrm{No} / \mathrm{mm}$ & $\mathrm{Mm}$ & $\mathrm{mm}^{2}$ & $\mathrm{Kg} / \mathrm{km}$ & $\mathrm{KN}$ & $\mathrm{Ohm} / \mathrm{km}$ & $\mathrm{A}$ \\
\hline Elk & $30 / 4.50$ & $7 / 4.50$ & 31.50 & 588.5 & 2196.0 & 198.30 & 0.06079 & 985 \\
\hline Camel & $54 / 3.35$ & $7 / 3.35$ & 30.15 & 537.7 & 1801.0 & 147.10 & 0.06080 & 985 \\
\hline
\end{tabular}

This paper therefore aims at designing a $750-\mathrm{kV}$ transmission grid for the Nigerian power system to ensure efficient transmission of the available power to the nation minimal losses and to also cater for future needs.

\section{ELECTRICAL DESIGN OF TRANSMISSION LINE II.I CHOICE OF CONDUCTOR}

From the extensive study of the existing $765-\mathrm{kV}$ transmission lines and other EHV systems in Brazil, USA and Canada [10], the popular choice of aluminum conductor is the Aluminum Conductor Steel Reinforced (ACSR). It comprises a stranded steel core which carries the mechanical load while layers of stranded aluminum serve as the actual conductors carrying the current. The main purpose of choosing the ACSR is to achieve a higher strength-to-weight ratio of the transmission line. Also, the stranding of the conductor offers more flexibility. The ACSR conductor specification for EHV transmission lines is as presented in Table 1.

The stated ACSR conductors are obtained from the British standard (BS-215) [11] system for conductors. From Table 1, it is observed that the camel conductor weighs less than both the moose and elk while the moose has the least resistance. However, in order to reduce losses in EHV transmission, the number of conductors per phase is often increased making the camel conductor more suitable because of its reduced weight. Therefore, elk and the moose conductor are not best suited for usage because of their excessive weight. The camel conductor having the lowest weight, and considerably high mechanical strength and a rating of $985 \mathrm{~A}$ is therefore selected.

\section{II.II CURRENT RATING OF THE LINE}

From the study of the existing $765-\mathrm{kV}$ transmission lines, it is observed that the lines are designed to transfer a typical power of 4,000 MVA and even more, the appropriate line current is calculated using equation (1):

$I=\frac{S}{V \sqrt{3}}$

$$
\begin{gathered}
I=\frac{4,000 \times 10^{6}}{750,000 \times \sqrt{3}} \\
I=3,079.20 \mathrm{~A}
\end{gathered}
$$

\section{II.III THE USE OF BUNDLE CONDUCTORS}

Due to the very high current rating of the transmission line, a system of 4 Camel conductors per phase is adopted amongst other systems such as 3,5,6 and 8 conductors per bundle. The 3 -conductor system doesn't provide a wide enough loading margin as well as the uneven nature of the bundling whereas for a 4-conductor bundle system, the total ampacity of each phase is 3,940A which already provides a wide enough margin when compared to the line current ratings $(3,079.20 \mathrm{~A})$.

\section{II.IV INSULATOR DESIGN}

From Ref. [12], it is inferred that glass, porcelain and composite are the three major materials used in insulator production, of which the most common practice is the use of porcelain insulators. For voltages above $33 \mathrm{kV}$, the suspension type insulators are the most economical [13]. It should be highly emphasized however that the choice of the type of these insulators also depends on the level of pollution of the environment.

The standard design is an arrangement of 32-35 porcelain insulators [14]. Each unit of the porcelain insulators discs has a maximum voltage rating of $25 \mathrm{kV}$. Therefore, the minimum number of units in a suspension string is calculated using equation (2):

$n=\frac{V}{25}$

where $V$ is nominal voltage in $\mathrm{kV}$.

These porcelain insulators generally have a creepage distance of $370 \mathrm{~mm}$ and mechanical failure load and no-load deformation strength of $210 \mathrm{kN}$ and $140 \mathrm{kN}$ (67\% of failure load) respectively.

The suspension insulators are to be attached to the cross arms of the towers depending on the type of tower and the Right of Way (ROW) requirement. There are two major configuration techniques: the "V" and the "I" strings. The I-string of insulator follows the conductor and sways like a pendulum in a strong side wind whereas the $\mathrm{V}$-strings prevent conductor movement at towers. The V-strings are mostly used for high voltage transmission system. This is not only to restrict conductor movement but to reduce ROW requirement as the

Table 2. Insulator Specifications

\begin{tabular}{l|l|l}
\hline Insulator String & Configuration & Number of Discs and Assembly \\
\hline Suspension String & V-90 & $2 \times 35 \times 210 \mathrm{kN}$ Double suspension \\
\hline Tension String & Quadruple & $4 \times 35 \times 210 \mathrm{kN}$ Quad suspension \\
\hline Pilot String & $\mathrm{I}$ & $1 \times 35 \times 140 \mathrm{kN}$ Double suspension \\
\hline
\end{tabular}


swaying nature of the I-string leads to an increase in ROW. This study tends to use a minimum amount of ROW and therefore prefers the V-strings to the I- string.

Furthermore, different types of strings are used depending on the function of the tower. The suspension strings are used on tangent towers where there are straight runs and the Stress is due to weight of line and wind load. The tension strings are used wherever the transmission line changes direction while the pilot strings are used wherever the tower begins or ends and often employ an I-string. A right angle is designed in between the two sets of strings of the V-configuration. The insulator specification is as presented in Table 2.

\section{II.V EARTH WIRE DESIGN}

The choice of material for the ground wire falls between galvanized steel and aluminium conductor. From a study of the sag and tension tables of both ground wire types, it is observed that the galvanized steel wires produce the least sag for a 400m span [11]. The galvanized steel series generally weighs more and possesses higher resistance than the aluminium series. The choice of ground wire for this study like the choice of conductor tends towards weight reduction and therefore chooses from the aluminium series displayed in Table 3.

Overall, a total of two ground wires were installed along both ends of the top of the steel towers. A shield angle of $15^{\circ}$ or $20^{\circ}$ is adopted for the outer phases of the $750-\mathrm{kV}$ line conductors while the middle phase shall fall below the circle drawn with two ground wire points as diameter.

\section{II.VI LINE PARAMETERS}

Line parameters are those properties of the transmission line that provide information about the state of the system. With line parameters, the losses, efficiency, the sending and receiving powers etc. can be determined. The line parameters are also used in simulations such as the load flow and contingency fault analysis.

\section{II.VII LINE RESISTANCE}

The resistance (RT) of the four-conductor bundle is calculated using equation (3):

$R_{T}=\frac{\rho L}{A}$

$\rho=$ Resistivity of Aluminum;

$A=$ Cross sectional Area of Aluminum in the bundle; and

$L=$ Length of the line $(1 \mathrm{~km})$.

On substituting, we have (for one conductor)

$$
R_{T}=\frac{2.8735 \times 10^{-8} \Omega \mathrm{m} \times 1000 \mathrm{~m}}{476.6 \times 10^{-6} \mathrm{~m}^{2} \times 4}
$$

\section{II.VIII GEOMETRIC MEAN DISTANCE (GMD AND GEOMETRIC MEAN RADIUS (GMR)}

In the evaluation of inductance of composite conductors, it is required to determine the Geometric Mean Distance (GMD) and the Geometric Mean Radius (GMR) of the parallel circuit as shown in Figure 1. Thus, the equivalent GMD and GMR are calculated using equations (4) and (5).

$$
\begin{gathered}
G M R=1.091 \sqrt[4]{r \cdot d^{3}} \\
G M R=1.091 \sqrt[4]{0.015075 \times 0.646^{3}} \\
G M R=0.2755 \mathrm{~m} \\
G M D=\sqrt[3]{D_{A B} \times D_{B C} \times D_{A C}} \\
G M D=\sqrt[3]{14 \times 14 \times 28} \\
G M D=17.64 \mathrm{~m}
\end{gathered}
$$

From the Electric Power Research Institute (EPRI) standards [15], the phase spacing for a horizontal arrangement of 800$\mathrm{kV}$ system of conductors is $14 \mathrm{~m}$ while the bundle diameter for a four-bundle conductor arrangement is $64.6 \mathrm{~cm}$. The radius of the camel conductor is $15.075 \mathrm{~mm}$.

where:

$r=$ Radius of the conductor;

$d=$ Bundle diameter; and

$D_{A B}, D_{B C}, D_{A C}=$ Distance between phase conductors.

\section{II.IX LINE INDUCTANCE AND INDUCTIVE REACTANCE}

The Line Inductance and Inductive Reactance are calculated using equations (6) and (7) respectively:

$$
\begin{gathered}
L=2 \times 10^{-7} \ln \frac{G M D}{e^{-1 / 4 G M R}} \\
L=2 \times 10^{-7} \ln \frac{17.64}{e^{-1 / 4} \times 0.2755} \times 1000 \mathrm{~m} \\
L=2 \times 10^{-7} \times \ln 82.2149 \\
L=0.8819 \mathrm{mH} / \mathrm{km} \\
X_{L}=2 \pi f L \quad X_{L}=2 \pi \times 50 \times 0.8819 \times 10^{-6} \\
X_{L}=0.2771 \Omega / \mathrm{km}
\end{gathered}
$$

\section{II.X LINE CONDUCTANCE}

This accounts for real power loss between conductors or between conductors and ground. In overhead lines, this power loss is due to leakage currents at insulators and the effects of corona. It is very often neglected because it is a small component of shunt admittance [16]. Therefore, line

\begin{tabular}{l|l|l|l|l|l|l}
\hline \multicolumn{9}{c}{ Table 3. Aluminum ground wires } \\
\hline \multirow{2}{*}{ Description } & $\begin{array}{l}\text { Overall } \\
\text { diameter }\end{array}$ & Nominal area & Approximate mass & $\begin{array}{l}\text { Rated } \\
\text { strength }\end{array}$ & $\begin{array}{l}\text { Coefficient } \\
\text { linear expansion }\end{array}$ & $\begin{array}{l}\text { Resistance } \\
20^{\circ} \mathrm{C}\end{array}$ \\
\cline { 2 - 8 } & $\mathrm{Mm}$ & $\mathrm{mm}^{2}$ & $\mathrm{Kg} / \mathrm{mm}$ & $\mathrm{Kgf}$ & $\mathrm{Per}{ }^{\circ} \mathrm{C}$ & Ohms \\
\hline $19 / 2.00$ & 10.00 & 59.70 & 164 & 1790 & $23 \times 106$ & 0.552 \\
\hline $7 / 3.81$ & 11.43 & 79.81 & 218 & 2387 & $23 \times 106$ & 0.4125 \\
\hline $19 / 2.46$ & 12.30 & 90.31 & 248 & 2576 & $23 \times 106$ & 0.3663 \\
\hline
\end{tabular}


Conductance, $G=0$

\section{II.XI LINE CAPACITANCE AND SUSCEPTANCE}

The Capacitance is calculated using equation (8):

$$
C=\frac{2 \pi \varepsilon_{O}}{\ln (G M D / G M R)}
$$

$$
\begin{gathered}
C=\frac{2 \pi \times 8.85 \times 10^{-12}}{\ln (17.64 / 0.2755)} \\
C=\frac{2 \times 3.142 \times 8.85 \times 10^{-12} \times 1000 m}{4.1593} \\
C=0.01337 \mu \mathrm{F} / \mathrm{km}
\end{gathered}
$$

The line Susceptance is calculated using equation (9):

\section{MATH}

Mechanical design of the transmission line involves the design of the support structures most especially the towers and determination of safe clearance levels. It involves the design of structures that do not come in contact directly with the flow of alternating current. The selection of basic tower configuration for an overhead transmission line is a function of several parameters such as the line voltage, number of circuits per tower and the conductor bundling. For EHV, care has to be taken to ensure that the tower is designed to reduce the environmental hazards that may arise from the electrical and magnetic fields, radio interference and audible noises. Depending on requirements for availability and necessary ROW, single, double or multiple circuits are erected. Single circuits are often preferred due to narrower ROW requirements. The mechanical design of towers involves the determination of the height, width, clearances level and ROW required for the transmission towers. It also involves specifying the type of material used, support structure and shape.

\section{III.I MATERIAL FOR TOWER CONSTRUCTION}

Several structures used in EHV transmission use materials such as Steel, Galvanized steel and Aluminum [12]. The structures are constructed of Galvanized steel because of its higher mechanical strength. Steel towers generally possess a longer life span and can thrive in extreme climatic conditions and allow for use of longer spans.

\section{III.II SUPPORT STRUCTURE}

As regards the support structure of the towers, a choice of selfsupporting horizontal structures is preferred over the guyed towers. Although guyed tower consumes a lesser amount of steel and other construction materials, the self-supporting structures allow for use of lesser ROW as shown Figures 2 and 3.

$$
B=2 \pi f C
$$

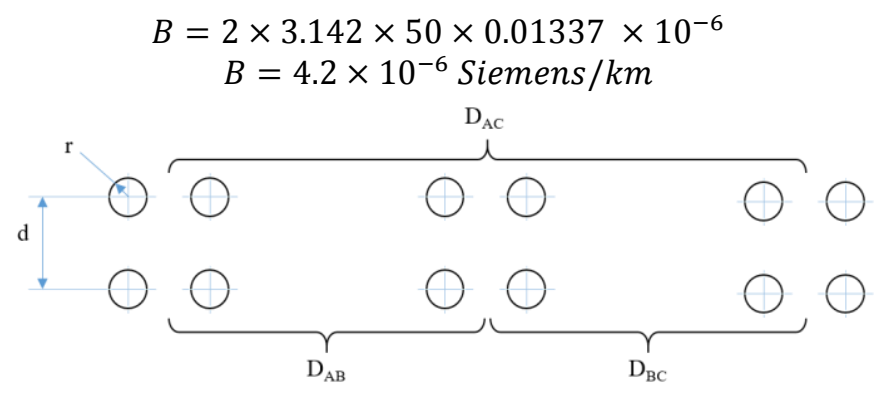

Fig. 1. Phase spacing and bundle spacing of conductors

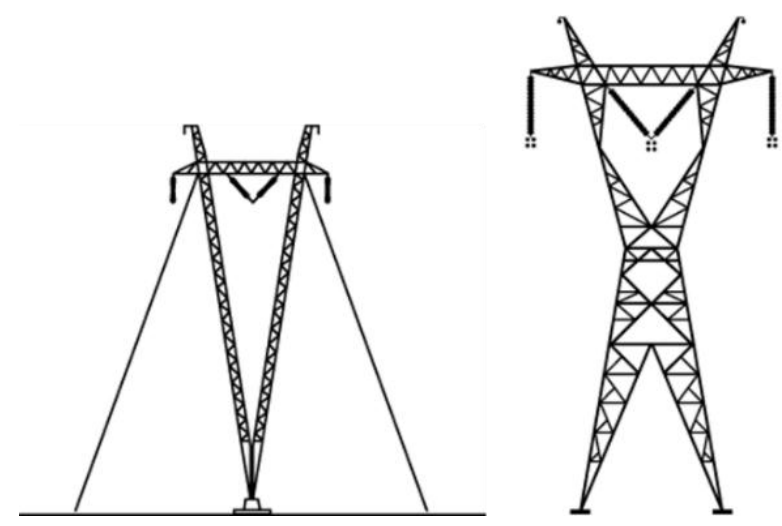

ig. 2. Horizontal type towers

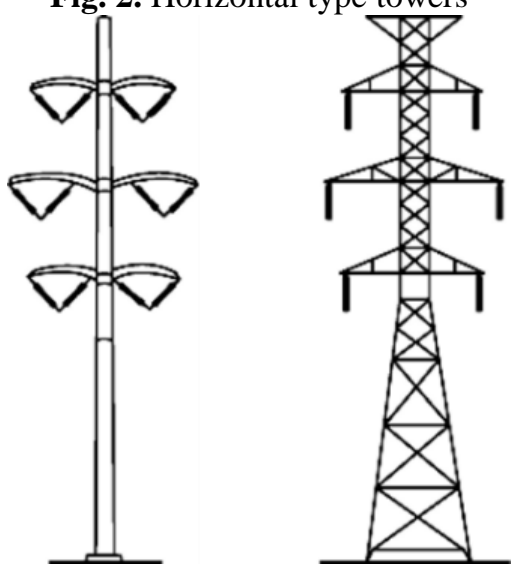

Fig. 3. Phase spacing and bundle spacing of conductors

\section{III.III CONDUCTOR ARRANGEMENT}

The conductor arrangement and the number of circuits also determine the type of tower that is chosen. The vertical type is generally often taller than the horizontal types. The horizontal shape of towers is adopted over the other common vertical shape type. This is because the vertical shape type is more economically suitable for a double-circuit system. The horizontal scheme also offers greater performance from the consideration of audible noise, radio interference and corona effect because more clearances can easily be obtained. 
Table 4. Developed 750-kV Line parameters to replace the existing 330-kV transmission lines

\begin{tabular}{|c|c|c|c|c|c|c|}
\hline \multicolumn{2}{|l|}{ BUS NAME } & \multirow{2}{*}{$\begin{array}{l}\text { LENGTH } \\
\mathrm{km}\end{array}$} & \multicolumn{2}{|c|}{ SERIES IMPEDANCE } & \multicolumn{2}{|c|}{ SHUNT ADMITTANCE } \\
\hline FROM & TO & & $\mathrm{R}$ (p.u) & X (p.u) & $\mathrm{G}(\mathrm{p} . \mathrm{u})$ & $\mathrm{B} / 2$ (p.u) \\
\hline Akamgbe & Ikeja-West & 17 & 0.0005 & 0.0084 & 0 & 0.0209 \\
\hline Ayede & Oshogbo & 115 & 0.0031 & 0.0566 & 0 & 0.1413 \\
\hline Ikeja-West & Egbin & 62 & 0.0017 & 0.0305 & 0 & 0.0762 \\
\hline Ikeja-West & Benin & 280 & 0.0075 & 0.1379 & 0 & 0.3441 \\
\hline Oshogbo & Jebba & 249 & 0.0067 & 0.1227 & 0 & 0.306 \\
\hline Jebba TS & Jebbs GS & 8 & 0.0002 & 0.0039 & 0 & 0.0098 \\
\hline Jebba TS & Shiroro & 244 & 0.0065 & 0.1202 & 0 & 0.2999 \\
\hline Jebba TS & Kainji & 81 & 0.0022 & 0.0399 & 0 & 0.0995 \\
\hline Kainji & Kebbi & 310 & 0.0083 & 0.1527 & 0 & 0.381 \\
\hline Shiroro & Kaduna & 96 & 0.0026 & 0.0473 & 0 & 0.118 \\
\hline Jos & Gombe & 265 & 0.0071 & 0.1305 & 0 & 0.3257 \\
\hline Benin & Sapele & 50 & 0.0013 & 0.0246 & 0 & 0.0615 \\
\hline Benin & Onitsha & 137 & 0.0037 & 0.0675 & 0 & 0.1684 \\
\hline Onitsha & New Heaven & 96 & 0.0026 & 0.0473 & 0 & 0.118 \\
\hline Onitsha & Alaoji & 138 & 0.0037 & 0.068 & 0 & 0.1696 \\
\hline Alaoji & Afam & 25 & 0.0007 & 0.0123 & 0 & 0.0307 \\
\hline Sapele & Aladja & 63 & 0.0017 & 0.031 & 0 & 0.0774 \\
\hline Delta & Aladja & 30 & 0.0008 & 0.0148 & 0 & 0.0369 \\
\hline Kainji GS & Jebba GS & 81 & 0.0022 & 0.0399 & 0 & 0.0995 \\
\hline Ayede & Ikeja-West & 137 & 0.0037 & 0.0675 & 0 & 0.1684 \\
\hline Egbin TS & $\mathrm{Aja}$ & 28 & 0.0007 & 0.0135 & 0 & 0.0338 \\
\hline Kaduna & Jos & 197 & 0.0053 & 0.097 & 0 & 0.2421 \\
\hline Jos & Maiduguri & 275 & 0.0074 & 0.1355 & 0 & 0.338 \\
\hline Oshogbo & Ikeja-West & 252 & 0.0068 & 0.1241 & 0 & 0.3097 \\
\hline Benin & Delta & 107 & 0.0029 & 0.0527 & 0 & 0.1315 \\
\hline Onitsha & Okpai & 80 & 0.0021 & 0.0394 & 0 & 0.0983 \\
\hline Geregu & Ajaokuta & 5 & 0.0001 & 0.0025 & 0 & 0.0061 \\
\hline Shiroro & Kaduna & 96 & 0.0026 & 0.0473 & 0 & 0.118 \\
\hline
\end{tabular}

The tower designations apply as follows:

1. Suspension towers for straight runs with angle of deviation of about $2^{\circ}-5^{\circ}$.

2. Several forms of tension towers (Type B, C, D and E) are used where the deviation angle exceeds $5^{\circ}$ but is less than $60^{\circ}$.

Other types of towers to be employed are the transposition towers for line transposition and the special suspension towers for river crossings and valley crossings with spans of about $1000 \mathrm{~m}$.

\section{III.IV TRANSMISSION CORRIDOR WIDTH AND ROW}

A ROW is a large components part of transmission line and helps to give a well-spaced margin among high-voltage lines and surrounding structures. ROW is used as access inspection at the ground-based and also during routine checkup or for maintenance/repair sake. Adequate ROW must be maintained to avoid ground faults.

Transmission corridor widths may or may not be equal to the width of the ROW that should be selected because the latter are determined by local requirements or by special technical or economic constraints. ROW is determined based on the line design and local conditions to limit construction which would interfere with the line operation. Currently, the cutting of trees has been limited to the trees that would interfere with the operation of the line. In areas with thick vegetation, it is often arranged with the owners of the ROW for trees outside the ROW to be removed to remove the danger of trees outside the 
International Journal of Engineering Research and Technology. ISSN 0974-3154, Volume 13, Number 9 (2020), pp. 2219-2229

(C) International Research Publication House. https://dx.doi.org/10.37624/IJERT/13.9.2020.2219-2229

Table 5. Load Flow Result of the 750-Kv Super Grid Simulation in MATLAB

\begin{tabular}{|c|c|c|c|c|c|c|c|}
\hline \multirow{2}{*}{ Bus No } & \multirow{2}{*}{ Voltage Mag. } & \multirow{2}{*}{ Angle Degree } & \multicolumn{2}{|l|}{ Load } & \multicolumn{2}{|c|}{ Generation } & \multirow{2}{*}{ Injected Mvar } \\
\hline & & & MW & Mvar & MW & Mvar & \\
\hline 1 & 0.937 & 6.238 & 114.500 & 85.900 & 0.000 & 0.000 & 0.000 \\
\hline 2 & 1.050 & 30.841 & 7.000 & 5.200 & 624.700 & 128.832 & 0.000 \\
\hline 3 & 1.030 & 23.635 & 0.000 & 0.000 & 495.000 & 183.406 & 0.000 \\
\hline 4 & 1.030 & 23.612 & 11.000 & 8.200 & 0.000 & 0.000 & 0.000 \\
\hline 5 & 0.916 & 3.022 & 201.200 & 150.900 & 0.000 & 0.000 & 0.000 \\
\hline 6 & 0.859 & -4.575 & 275.800 & 206.800 & 0.000 & 0.000 & 0.000 \\
\hline 7 & 0.884 & -3.022 & 0.000 & 0.000 & 154.800 & 0.000 & 0.000 \\
\hline 8 & 0.894 & -3.932 & 633.200 & 474.000 & 0.000 & 0.000 & 0.000 \\
\hline 9 & 0.866 & -5.448 & 244.700 & 258.500 & 0.000 & 0.000 & 0.000 \\
\hline 10 & 1.050 & 0.000 & 68.900 & 51.700 & 738.421 & 845.696 & 0.000 \\
\hline 11 & 1.034 & -1.448 & 274.400 & 205.800 & 0.000 & 0.000 & 0.000 \\
\hline 12 & 1.012 & -14.872 & 290.100 & 145.000 & 0.000 & 0.000 & 0.000 \\
\hline 13 & 0.950 & 0.029 & 0.000 & 0.000 & 100.600 & 0.000 & 0.000 \\
\hline 14 & 0.971 & -0.867 & 383.300 & 287.500 & 0.000 & 0.000 & 0.000 \\
\hline 15 & 1.050 & 4.046 & 20.600 & 15.400 & 190.300 & 374.551 & 0.000 \\
\hline 16 & 1.048 & -10.632 & 13.800 & 10.300 & 0.000 & 0.000 & 0.000 \\
\hline 17 & 1.050 & 9.849 & 0.000 & 0.000 & 670.000 & 192.500 & 0.000 \\
\hline 18 & 1.042 & 7.379 & 96.500 & 72.400 & 0.000 & 0.000 & 0.000 \\
\hline 19 & 0.934 & 13.078 & 184.600 & 138.400 & 0.000 & 0.000 & 0.000 \\
\hline 20 & 1.050 & 30.128 & 0.000 & 0.000 & 750.000 & 367.842 & 0.000 \\
\hline 21 & 0.855 & 7.292 & 177.000 & 133.400 & 0.000 & 0.000 & 0.000 \\
\hline 22 & 0.997 & 10.740 & 427.000 & 320.200 & 0.000 & 0.000 & 0.000 \\
\hline 23 & 1.050 & 13.121 & 52.500 & 39.400 & 431.000 & 470.351 & 0.000 \\
\hline 24 & 1.050 & -1.435 & 70.300 & 36.100 & 388.900 & 308.104 & 0.000 \\
\hline 25 & 0.867 & -16.511 & 220.600 & 142.900 & 0.000 & 0.000 & 0.000 \\
\hline 26 & 0.991 & -10.140 & 193.000 & 144.700 & 0.000 & 0.000 & 0.000 \\
\hline 27 & 1.006 & -16.800 & 70.300 & 52.700 & 0.000 & 0.000 & 0.000 \\
\hline 28 & 1.036 & -20.289 & 130.600 & 97.900 & 0.000 & 0.000 & 0.000 \\
\hline 29 & 1.067 & -17.691 & 52.500 & 39.400 & 0.000 & 0.000 & 0.000 \\
\hline 30 & 1.043 & -22.713 & 66.500 & 47.800 & 0.000 & 0.000 & 0.000 \\
\hline 31 & 1.053 & -21.947 & 61.440 & 44.210 & 0.000 & 0.000 & 0.000 \\
\hline 32 & 1.042 & -15.036 & 88.500 & 60.300 & 0.000 & 0.000 & 0.000 \\
\hline Total & & & 4429.84 & 3275.01 & 4543.721 & 2871.283 & 0 \\
\hline
\end{tabular}

Real power loss $=4543.721-4429.940=113.781 \mathrm{MW}$ ROW falling across the line. The transmission corridor width is therefore the distance measured from the ROW centerline where audible noise, radio interference and television interference fall within acceptable levels. The minimum signal to noise ratio should be 30 . Also, the Audio noise level for 750-kV system should be less than $55 \mathrm{~dB}$ (A).. Most acceptable transmission corridor for $765 \mathrm{kV}$ reviewed fall within the $60-88 \mathrm{~m}$ range but in this study, $64 \mathrm{~m}$ is adopted.

\section{III.V THE TRANSMISSION TOWER}

The choice of transmission tower is a horizontal, selfsupporting galvanized steel tower. The tower is designed using the clearance levels and the EPRI [15] standards for $800-\mathrm{kV}$ towers. The single circuit nature of the power system ensures that the horizontal type is chosen over the vertical types. The distance between conductors of each phase as used in the calculation of the GMD is $14 \mathrm{~m}$. This decision ensures 
that the width of the tower exceeds $28 \mathrm{~m}$ i.e. the total distance between the conductors at the ends of the tower minimum. The height of the tower is also chosen to exceed the sum of the ground and the mid-span clearances as shown Figure 4.

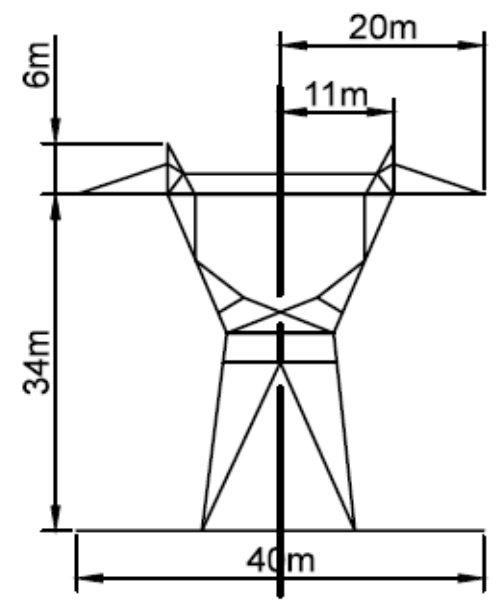

Fig. 4. Galvanized Steel towers for $750 \mathrm{kV}$

\section{III.VI CLEARANCES}

Clearance levels adopted are as follows:

1. Ground clearance: In order for environmental criteria such as radio and television interference and audible noises to be met, the minimum height clearance according to the EPRI [15] for a $765 \mathrm{kV}$ is between 13.7 to $16.5 \mathrm{~m}$, while the lowest bundle height to earth at structure is $28 \mathrm{~m}$.

2. Flood level clearance: the minimum Clearance above rivers and lakes is about $9.4 \mathrm{~m}$ or at least $3.05 \mathrm{~m}$ above maximum flood level.

3. Clearance and swing angles: for V-string with no swing angle, the stipulated clearance is $5 \mathrm{~m}$. The Istring, depending on the swing, has clearances varying from $1.3 \mathrm{~m}$ to $5.1 \mathrm{~m}$

4. Rail track crossing: Where railroad tracks are parallel to or crossed by overhead lines, all portions of the supporting structures, support arms, anchor guys, and equipment attached thereto less than $6.7 \mathrm{~m}$ above the nearest track rail shall have horizontal clearances not less than the values[17].

Mid-span clearance: This is the distance between ground and the center of the span of the conductor and is given as $12.4 \mathrm{~m}$ [18].

\section{III.VII CORONA LOSSES}

The effects of corona are important especially for Extra High Voltage transmission lines. Corona discharge is formed when the electric field formed at the surface of the transmission line conductor becomes so large that it starts to breakdown the surrounding air $(30 \mathrm{kV} / \mathrm{cm}$ during fair weather) thereby producing ionization of the area close to the conductor. It can be detected due to its visible light in form of purple glow consisting of micro arcs and its sound can be heard through its hissing and cracking sound. The oscillatory nature of the discharge generates high frequency and short-current pulses which lead to significant power loss as well as interference with radio and television signals. The effect of the formation of corona is not limited to only losses in the transmission line but also audible noises and visible flashes.

The level of corona is greatly affected by the size of the conductor, spacing between conductors, the line voltage and the atmospheric conditions. Surface impurities such as water droplets cause field concentration which enhances corona discharge. Thus, during bad weather, corona discharge is more intense and losses are far greater. Rough surfaces are more liable to corona because the unevenness of the surface decreases the value of the breakdown voltage. The smelling of the presence of ozone production is noticed during corona activity. The effects of corona are cumulative and permanent and the failure can occur without warning [19].

\section{III.VIII DISRUPTIVE CRITICAL VOLTAGE}

This is the minimum phase to neutral voltage at which corona occurs. In order for corona to occur, the value of $g$ must be equal to the breakdown strength of air $g_{o}$. The expression in equation (10) is under standard conditions: pressure at $76 \mathrm{cmHg}$, temperature of $25^{\circ} \mathrm{C}$

The disruptive critical voltage of the transmission line is thus calculated as follows:

$V_{c}=21.2 m_{c} \cdot \delta \cdot r \ln \frac{D}{r}$

where

$\mathrm{Mc}=$ surface irregularity factor, 0.90 for cables with more than 7 strands;

$\delta=$ air density factor $=1.0$; and

$\mathrm{D}=$ distance between phase conductor in $\mathrm{cm}$.

Therefore,

$$
\begin{gathered}
V_{c}=21.2 \times 0.90 \times 1 \times 1.5075 \times \ln \frac{1400}{1.5075} \\
V_{c}=196.56 \mathrm{kV}
\end{gathered}
$$

\section{III.IX VISUAL CORONA VOLTAGE}

This is the minimum phase to neutral voltage at which visible flashes and glows begin to appear along the transmission line conductors.

The visual corona voltage is calculated using equation (11):

$V_{v}=21.2 m_{V} \cdot \delta \cdot r\left(1+\frac{0.3}{\sqrt{\delta r}}\right) \ln \frac{D}{r}$

where

$\mathrm{Mv}=$ surface irregularity factor $=0.83$ for stranded wires

$$
\begin{gathered}
V_{v}=21.2 \times 0.83 \times 1 \times 1.5075 \\
\times\left(1+\frac{0.3}{\sqrt{1 \times 1.5075}}\right) \ln \left(\frac{1400}{1.5075}\right) \\
V_{v}=222.85 \mathrm{kV}
\end{gathered}
$$

\section{III.X POWER LOSSES DUE TO CORONA}

The Power losses due to the formation of corona using the Peterson's formula is calculated using equation (12): 
International Journal of Engineering Research and Technology. ISSN 0974-3154, Volume 13, Number 9 (2020), pp. 2219-2229

(C) International Research Publication House. https://dx.doi.org/10.37624/IJERT/13.9.2020.2219-2229

$P_{c}=\frac{0.545}{\delta}\left(V-V_{c}\right) \sqrt{r / G M D}$

where

$V=$ Voltage in-kV to neutral

$V_{c}=$ Disruptive critical voltage

$$
\begin{gathered}
P_{c}=\frac{0.545}{1} \times\left(\frac{750}{\sqrt{3}}-196.56\right) \times \sqrt{\frac{1.5075}{1764}} \\
P_{c}=3.767 \mathrm{~kW} / \mathrm{km}
\end{gathered}
$$

\section{CALCULATION OF THE DIMENSIONS OF THE LINE PARAMETERS AND RESULTS ANALYSIS}

\begin{tabular}{|c|c|c|c|c|c|c|}
\hline \multicolumn{7}{|c|}{ Table 6: Load-flow result of the existing 330-kV network } \\
\hline From Bus & To Bus & $\begin{array}{l}\text { Active Power } \\
\text { flow (MW) }\end{array}$ & $\begin{array}{l}\text { Reactive Power } \\
\text { flow (Mvar) }\end{array}$ & $\begin{array}{l}\text { Complex Power } \\
\text { flow (MVA) }\end{array}$ & $\begin{array}{l}\text { Active Power } \\
\text { loss (MW) }\end{array}$ & $\begin{array}{l}\text { Reactive Power } \\
\text { loss (Mvar) }\end{array}$ \\
\hline 1 & 2 & 115.9879 & -30.7254 & 119.9885 & 1.4879 & -116.625 \\
\hline 1 & 3 & 501.7121 & -55.2062 & 504.7403 & 6.633 & -11.5062 \\
\hline 2 & 1 & -114.5 & -85.9 & 143.14 & 1.4879 & -116.625 \\
\hline 3 & 1 & -495.079 & 43.7 & 497.0041 & 6.633 & -11.5062 \\
\hline 3 & 4 & -494.329 & -38.5246 & 495.8279 & 0.671 & -2.3843 \\
\hline 3 & 5 & 321.8366 & 13.46 & 322.1179 & 5.6016 & -78.1002 \\
\hline 3 & 23 & 656.5715 & -26.8354 & 657.1197 & 26.6503 & 75.2551 \\
\hline 4 & 3 & 495 & 36.1403 & 496.3176 & 0.671 & -2.3843 \\
\hline 5 & 3 & -316.235 & -91.5602 & 329.2231 & 5.6016 & -78.1002 \\
\hline 5 & 6 & 177.026 & 42.3656 & 182.0249 & 1.5765 & -71.7504 \\
\hline 5 & 8 & 128.921 & 11.3987 & 129.4239 & 1.0055 & -93.4136 \\
\hline 5 & 13 & -190.912 & -113.104 & 221.9008 & 3.238 & -172.597 \\
\hline 6 & 5 & -175.45 & -114.116 & 209.2965 & 1.5765 & -71.7504 \\
\hline 6 & 7 & -80.9763 & -36.6775 & 88.8954 & 0.1617 & -34.9959 \\
\hline 6 & 8 & \begin{tabular}{|l|}
-19.3741 \\
\end{tabular} & -56.0066 & 59.2629 & 0.0222 & -98.1078 \\
\hline 7 & 6 & 81.138 & 1.6816 & 81.1554 & 0.1617 & -34.9959 \\
\hline 7 & 8 & \begin{tabular}{|l|}
73.662 \\
\end{tabular} & -1.6816 & 73.6812 & 0.0577 & -17.1578 \\
\hline 8 & 5 & -127.916 & -104.812 & 165.3723 & 1.0055 & -93.4136 \\
\hline 8 & 6 & \begin{tabular}{|l|}
19.3963 \\
\end{tabular} & -42.1012 & 46.3544 & 0.0222 & -98.1078 \\
\hline 8 & 7 & -73.6044 & -15.4763 & 75.2138 & 0.0577 & -17.1578 \\
\hline 8 & 9 & 247.6955 & 235.7035 & 341.9199 & 2.9955 & -22.7965 \\
\hline 8 & 10 & -403.892 & -362.05 & 542.4106 & 6.4373 & 2.3304 \\
\hline 8 & 12 & -44.8346 & -59.1121 & 74.1915 & 1.2761 & -96.9254 \\
\hline 8 & 13 & -250.045 & -126.151 & 280.0656 & 6.7175 & -147.384 \\
\hline 9 & 8 & -244.7 & -258.5 & 355.9499 & 2.9955 & -22.7965 \\
\hline 10 & 8 & 410.3295 & 364.3806 & 548.7654 & 6.4373 & 2.3304 \\
\hline 10 & 11 & \begin{tabular}{|l|}
276.706 \\
\end{tabular} & 169.1378 & 324.3051 & 2.306 & -36.6622 \\
\hline 10 & 13 & -196.716 & 18.1493 & 197.5513 & 2.8778 & -27.954 \\
\hline 11 & 10 & \begin{tabular}{|l|}
-274.4 \\
\end{tabular} & -205.8 & 343 & 2.306 & -36.6622 \\
\hline 12 & 8 & 46.1107 & -37.8133 & 59.6326 & 1.2761 & -96.9254 \\
\hline 12 & 13 & 54.4893 & 37.8133 & 66.3244 & 0.3626 & -83.348 \\
\hline 13 & 5 & 194.15 & -59.4926 & 203.0606 & 3.238 & -172.597 \\
\hline 13 & 8 & 256.7627 & -21.2328 & 257.6391 & 6.7175 & -147.384 \\
\hline 13 & 10 & 199.5937 & -46.1033 & 204.8491 & 2.8778 & -27.954 \\
\hline 13 & 12 & \begin{tabular}{|l}
-54.1266 \\
\end{tabular} & -121.161 & 132.7018 & 0.3626 & -83.348 \\
\hline 13 & 14 & \begin{tabular}{|l|}
14.1681 \\
\end{tabular} & -155.65 & 156.2934 & 0.3681 & -165.95 \\
\hline 13 & 15 & -262.415 & -26.9578 & 263.7962 & 1.1368 & -36.8382 \\
\hline 13 & 16 & -473.901 & 20.0871 & 474.3261 & 4.7811 & -12.9197 \\
\hline 13 & 18 & -257.532 & 123.0107 & 285.4022 & 4.4327 & -70.3566 \\
\hline 14 & 13 & -13.8 & -10.3 & 17.22 & 0.3681 & -165.95 \\
\hline
\end{tabular}

Table 6: Load-flow result of the existing 330-kV network

This section employs the electrical and mechanical design methodology to calculate the dimension for the following line parameters: series impedance; shunt impedance; base impedance; and base admittance using equations (13), (14), (15) and (16) respectively. These values are then converted to their per unit values for simplicity. The results of surge impedance loading of the $750-\mathrm{kV}$ transmission line and the calculated values of single circuit impedances and admittances are also obtained.

\section{IV.I LINE PARAMETERS}

For the $750-\mathrm{kV}$ transmission line, the line parameters are calculated as follows: 
International Journal of Engineering Research and Technology. ISSN 0974-3154, Volume 13, Number 9 (2020), pp. 2219-2229

(C) International Research Publication House. https://dx.doi.org/10.37624/IJERT/13.9.2020.2219-2229

\begin{tabular}{|l|l|l|l|l|l|l|}
\hline 15 & 13 & 263.552 & -9.8805 & 263.7372 & 1.1368 & -36.8382 \\
\hline 15 & 17 & -93.852 & 3.7389 & 93.9265 & 0.2026 & -50.8631 \\
\hline 16 & 13 & 478.6817 & -33.0068 & 479.8183 & 4.7811 & -12.9197 \\
\hline 16 & 17 & 191.3183 & -28.4304 & 193.4192 & 0.7637 & -46.2284 \\
\hline 17 & 15 & 94.0547 & -54.602 & 108.755 & 0.2026 & -50.8631 \\
\hline 17 & 16 & -190.555 & -17.798 & 191.384 & 0.7637 & -46.2284 \\
\hline 18 & 13 & 261.9648 & -193.367 & 325.6017 & 4.4327 & -70.3566 \\
\hline 18 & 19 & -703.819 & 82.449 & 708.6316 & 46.1812 & 14.2387 \\
\hline 18 & 20 & 178.7979 & 112.9396 & 211.4806 & 1.7979 & -20.4604 \\
\hline 18 & 22 & 78.4561 & -140.421 & 160.8525 & 7.0193 & -97.1128 \\
\hline 19 & 18 & 750 & -68.2103 & 753.0954 & 46.1812 & 14.2387 \\
\hline 20 & 18 & -177 & -133.4 & 221.6406 & 1.7979 & -20.4604 \\
\hline 21 & 22 & 378.5 & 359.6307 & 522.1077 & 22.9367 & -3.8779 \\
\hline 22 & 18 & -71.4367 & 43.3086 & 83.5394 & 7.0193 & -97.1128 \\
\hline 22 & 21 & -355.563 & -363.509 & 508.4916 & 22.9367 & -3.8779 \\
\hline 23 & 3 & -629.921 & 102.0904 & 638.1404 & 26.6503 & 75.2551 \\
\hline 23 & 24 & 294.9635 & 64.7522 & 301.9873 & 4.8635 & -80.2478 \\
\hline 23 & 25 & 653.5577 & 486.4913 & 814.7463 & 21.1085 & 145.1124 \\
\hline 24 & 23 & -290.1 & -145 & 324.3193 & 4.8635 & -80.2478 \\
\hline 25 & 23 & -632.449 & -341.379 & 718.7013 & 21.1085 & 145.1124 \\
\hline 25 & 26 & 230.5674 & 155.9158 & 278.3362 & 9.9674 & 13.0158 \\
\hline 25 & 27 & 208.8818 & 40.7631 & 212.8221 & 4.8743 & -25.2542 \\
\hline 26 & 25 & -220.6 & -142.9 & 262.8398 & 9.9674 & 13.0158 \\
\hline 27 & 25 & -204.008 & -66.0173 & 214.4233 & 4.8743 & -25.2542 \\
\hline Total & & & & & 203.62 & -1556.45 \\
\hline & & & & & \\
\hline
\end{tabular}

Series Impedance:

$Z=R+j X$

$Z=0.01507+j 0.2771 \Omega / k m$

Shunt Admittance:

$Y=G+j B$

$$
Y=0+j 4.2 \times 10^{-6} \mathrm{~S} / \mathrm{km}
$$

\section{IV.II LINE MODELLING}

The determination of the line parameters is carried out using the per unit system, the base impedance is calculated using equation (15) while the base admittance is directly obtained using equation (16). Typical base value of 1,000 MVA is adopted for the $750-\mathrm{kV}$ transmission grid system. That is

$V_{\text {base }}=V_{\text {line }}=750 \mathrm{kV}$

$Z_{\text {base }}=\frac{\left(V_{\text {base }}\right)^{2}}{M V A_{\text {base }}}$

$$
\begin{aligned}
& \begin{array}{c}
Z_{\text {base }}=\frac{(750,000)^{2}}{1000 \times 10^{6}} \\
Z_{\text {base }}=562.5 \Omega
\end{array} \\
& Y_{\text {base }}=\frac{1}{z_{\text {base }}} \\
& Y_{\text {base }}=\frac{1}{562.5} \\
& Y_{\text {base }}=1.709 \times 10^{-3} \text { Siemens }
\end{aligned}
$$

\section{IV.III COMPUTATION OF PER UNIT VALUES}

Per unit system (which is the ratio of the actual value to the base) is calculated for resistance Rp.u, reactance Xp.u, and susseptance Bp.u using equations (17), (18) and (19) respectively as follows:

$$
R_{p . u}=\frac{R_{\text {actual value }}}{Z_{\text {base }}}
$$

$$
X_{p . u}=\frac{X_{\text {actual value }}}{Z_{\text {base }}}
$$

$$
\begin{gathered}
R_{p . u}=\frac{0.01507}{562.5} \\
R_{p . u}=0.00002679 \mathrm{pu} / \mathrm{km}
\end{gathered}
$$

$$
\begin{aligned}
X_{p . u} & =\frac{0.2771}{562.5} \\
X_{\text {p.u }}= & 0.0004926 \mathrm{pu} / \mathrm{km} \\
B_{\text {p.u }}=\frac{B_{\text {actualvalue }}}{Y_{\text {base }}} & \\
B_{\text {p.u }} & =\frac{4.2 \times 10^{-6}}{1.709 \times 10^{-3}} \\
B_{\text {p.u }} & =0.002458 \mathrm{pu} / \mathrm{km}
\end{aligned}
$$

Per Unit Series Impedance:

Per unit impedance is obtained using equation (20):

$Z=R+j X$

$Z=0.00002679+j 0.0004926 \mathrm{pu} / \mathrm{km}$

Per Unit Shunt Admittance:

Per unit shunt admittance is obtained using equation (21): $Y=G+j B$

$$
Y=0+j 0.002458 \mathrm{pu} / \mathrm{km}
$$

\section{IV.IV CALCULATION OF THE SURGE IMPEDANCE LOADING (SIL) OF THE 750-KV TRANSMISSION LINE}

The surge impedance loading is defined as the load at which the reactive power absorbed by the inductance of the line is equal to the reactive power supplied by the capacitance of the line. It is the power delivered by a lossless line to a load resistance equal to the surge of characteristic impedance. SIL mainly depends on voltage class and the conductor 
configuration of the line. For the load equal to the SIL, the voltage of the line does not change along the length of the line hence no extra compensation for reactive power is required. This means that at SIL, the transmission line consumes as much reactive power as it generates and the terminal voltages are equal to each other. SIL, characteristic impedance and power of SIL are therefore calculated using equations (22), (23) and (24) respectively.

$$
\begin{aligned}
& P_{S I L}=\frac{V^{2}}{Z_{C}} \\
& Z_{C}=\sqrt{\frac{z}{Y}}
\end{aligned}
$$

$$
\begin{aligned}
& Z_{C}= \sqrt{\frac{0.01507+j 0.2771}{4.2 \times 10^{-6}}} \\
& Z_{C}=\sqrt{3588.1+j 65,976.2} \\
& Z_{C}=\sqrt{66,073.7} \\
& Z_{C}=257.04 \Omega
\end{aligned}
$$

$$
P_{S I L}=\frac{V^{2}}{z_{C}}
$$

$$
\begin{gathered}
P_{S I L}=\frac{750,000^{2}}{257.04} \\
P_{S I L}=2,188.38 \mathrm{MW}
\end{gathered}
$$

This implies that in order to maintain stability in the lines, the transmission capacity is limited to the Surge Impedance Loading (SIL) of 2,188.38 MW. This power transfer capability can be improved by increasing the SIL level. The SIL level can be increased by reduction in the transmission line inductance. This can be made possible by [20]:

1. Increasing bundle spacing;

2. Increase in diameter of conductor; and

3. Reduction in phase to phase spacing.

The calculated line parameters are then taken into account for the upgrade to be possible. The conductors are replaced with conductors with higher current capacity. Therefore, the 'Bersimis' two conductor bundle for the $330 \mathrm{kV}$ is upgraded to a four Camel conductor bundle based on the design. Therefore, the result of the line parameters for all the existing lines in the $330-\mathrm{kV}$ transmission system is developed as a representation of $750-\mathrm{kV}$ transmission system. Table 3 shows the developed line parameters for $750-\mathrm{kV}$ transmission line.

In accordance with the developed $750-\mathrm{kV}$ transmission line data of Table 4, a power-flow analysis was carried out and the result showed a $44.2 \%$ large reduction in the power losses when compared with the existing $330-\mathrm{kV}$ transmission line. The real power losses in the $750-\mathrm{kV}$ transmission line amounted to $113.781 \mathrm{MW}$ while that of the existing $330-\mathrm{kV}$ is 203.62 MW as shown in Tables 5 and 6 respectively.

\section{CONCLUSIONS}

The study successfully designed a 750-kV Super grid transmission line together with its major components: the conductors, insulators and the steel tower providing detailed specifications for each of the above. Transmission line data was successfully formulated to aid in various power system analyses and to also determine other transmission line properties. The study also showed that the implementation of a $750-\mathrm{kV}$ grid in Nigeria results in a significant reduction in the systems' power losses. This is because a $44.2 \%$ Power loss reduction was confirmed upon comparing the $750-\mathrm{kV}$ line losses with the 330-kV line losses.

The result of voltage analysis of the $750-\mathrm{kV}$ also showed reasonable and appreciable values better than the existing $330-\mathrm{kV}$ network. The implementation of the designed $750-\mathrm{kV}$ grid is guaranteed to ensure a more stable power system with reduced losses and also eradicate the erratic nature of the present $330-\mathrm{kV}$ transmission line in Nigeria. A stable power system in return ensures improved standard of living and a growing economy.

\section{ACKNOWLEDGEMENTS}

The authors wish to acknowledge the management of Covenant University for her part sponsorship and support toward the success of this research work.

\section{REFERENCES}

[1] L. F. Ochoa, R. M. Ciric, A. Padilha-Feltrin, and G. P. Harrison, "Evaluation of distribution system losses due to load unbalance," in 15th PSCC, 2005, vol. 6, pp. 1-4.

[2] H. Huang, D. Kumar, V. Ramaswami, and D. Retzmann, "UHV 1200 kV AC Transmission," in Power Transmission and Distribution (GRIDTECH), 2007.

[3] W. Inc. (2019). World population. Available: www.worldometers.info/world-population/nigeriapopulation/

[4] C. O. Awosope, "Nigeria electricity industry: issues, challenges and solutions," Covenant University 38th Public Lecture, 2014

[5] A. Abdulkareem, C. Awosope, and A. Awelewa, "On The Cost Implications of Technical Energy Losses on Nigerian 330-kV Transmission Grid System," International Journal of Science and Research (IJSR), pp. 1289-1299, 2013.

[6] A. Abdulkareem, C. Awosope, A. Adoghe, and S. Alayande, "Investigating the Effect of Asymmetrical Faults at Some Selected Buses on the Performance of the Nigerian 330-kV Transmission System," International Journal of Applied Engineering Research, vol. 11, no. 7, pp. 5110-5122, 2016.

[7] N. P. Reform. (2019). Available: www.nigeriapowerreform.org

[8] T. W. Bank. (2019). Electric power consumption (kWh per capita). Available: https://data.worldbank.org/indicator/EG.USE.ELEC.K H.PC

[9] IndexMundi. (2019). Available: www.indexmundi.com 
[10] D. F. Warne, Newnes Electrical Power Engineer's Handbook (Second edition). Newnes, June 27, 2005

[11] DiamondPower. (2019). Conductor Technical Catalogue. Available: http://www.dicabs.com/

[12] R. Lings, V. Chartier, and P. S. Maruvada, "Overview of Transmission Lines Above $700 \mathrm{kV}$," in IEEE PES 2005 Conference and Exposition in Africa, Durban, South Africa, 11-15 July, 2005.

[13] B. L. Theraja and A. K. Theraja, A Textbook Of Electrical Technology. S. Chand Publishing, 2006.

[14] D. lee, "Korea Corner: $765 \mathrm{kV}$ Transmission Technology Development in Korea," EINA, no. 17, pp. 35-38, 2010.

[15] P. R. I. Electric, Transmission LIne Reference Book: $345 \mathrm{kV}$ and Above. Second Edition, revised, EL-2500, 1982.

[16] D. J., Glover, S. Mulukutla, Sarma, and O. Thomas, "Power system analysis and design," 2011, p. 117.

[17] I. o. E. a. E. Engineering, National Electricity Safety Code (NESC). New York: IEEE, 1997.

[18] R. B. Laughlin, "Standard Parameters of 800 kV Class Transmission Systems in India," Accessed on: December 21, Available: http://large.stanford.edu/publications/coal/references/ce a/

[19] T. Alumona, L, "Overview Of Losses And Solutions In Power Transmission Lines," IISTE, vol. 4, no. 8, pp. 24-31, 2014.

[20] P. Varun and G. J., Jamnani, "Improving Power Transfer Capability of EHV AC Double circuit Transmission line by Enhancing Surge Impedance Loading level," International Journal of Engineering Research and Development, pp. 41-48, April, 2015. 